\title{
Nutrição no pós-genoma: fundamentos e aplicações de ferramentas ômicas
}

\author{
Nutrition in the post-genome era: 'omic' \\ tools basics and applications
}

\author{
Eliane FIALHO' \\ Fernando Salvador MORENO² \\ Thomas Prates ONG ${ }^{3}$
}

\section{R E S U M O}

Após seqüenciamento do genoma humano, os estudos genômicos têm se voltado à elucidação das funções de todos os genes, bem como à caracterização de suas interações com fatores ambientais. A nutrigenômica surgiu no contexto do pós-genoma humano e é considerada área-chave para a nutrição nesta década. Seu foco de estudo baseia-se na interação gene-nutriente. Esta ciência recente tem como objetivo principal o estabelecimento de dietas personalizadas, com base no genótipo, para a promoção da saúde e a redução do risco de doenças crônicas não transmissíveis como as cardiovasculares, o câncer, o diabetes, entre outras. Nesse contexto, é fundamental a aplicação na área de nutrição das ferramentas de genômica funcional para análise do transcritoma (transcritômica), do proteoma (proteômica) e do metaboloma (metabolômica). As aplicabilidades dessas metodologias em estudos nutricionais parecem ilimitadas, pois podem ser conduzidas em cultura de células, modelos de experimentação em animais, estudos pré-clinicos e clínicos. Tais técnicas apresentam potencial para identificar biomarcadores que respondem especificamente a um determinado nutriente ou composto bioativo dos alimentos e para estabelecer as melhores recomendações dietéticas individuais para redução do risco das doenças crônicas não transmissíveis e promoção da saúde.

Termos de indexação: Nutrição em saúde pública. Nutrigenômica. Transcritômica. Proteômica.

\section{A B S T R A C T}

After sequencing the human genome, genomic studies have been focusing on elucidating the function of all genes, as well as characterizing their interactions with environmental factors. Nutrigenomics emerged in the

\footnotetext{
1 Universidade Federal do Rio de Janeiro, Instituto de Nutrição Josué de Castro, Departamento de Nutrição Básica e Experimental. Rio de Janeiro, RJ, Brasil.

2 Universidade de São Paulo, Faculdade de Ciências Farmacêuticas, Departamento de Alimentos e Nutrição Experimental, Laboratório de Dieta, Nutrição e Câncer. São Paulo, SP, Brasil.

3 Universidade de São Paulo, Faculdade de Ciências Farmacêuticas, Departamento de Alimentos e Nutrição Experimental, Laboratório de Dieta, Nutrição e Câncer. Av. Prof. Lineu Prestes, 580, Bloco 14, 05508-900. São Paulo, SP, Brasil. Correspondência para/Correspondence to: T.P. ONG. E-mail: <tong@usp.br>.
} 
pos-genome era and is considered a key-area for nutrition in the present decade. Its research focus is nutrientgene interaction. The main objective of this recent science is to establish personalized genotype-based diets that promote health and reduce the risk of non-communicable chronic diseases such as cardiovascular diseases, cancer, diabetes and others. In this context, it is essential to use functional genomic tools to analyze the transcriptome (transcriptomics), proteome (proteomics) and metabolome (metabolomics) in the field of nutrition. The applicabilities of such methodologies in nutritional studies seem unlimited since they can be conducted in cell cultures, animal models and pre-clinical and clinical studies. Such techniques may allow one to identify biomarkers that respond specifically to a certain dietary nutrient or bioactive compound and to establish the best individual dietary advice to reduce the risk of non-communicable chronic diseases and promote health.

Indexing terms: Nutrition public health. Nutrigenomics. Transcriptomics. Proteomics.

\section{N T R O D U Ç Ã O}

Após seqüenciamento do genoma humano, os estudos genômicos têm se voltado à elucidação das funções de todos os genes, bem como à caracterização de suas interações com fatores ambientais ${ }^{1,2}$. A nutrigenômica surgiu no contexto do pós-genoma humano e é considerada área-chave para a nutrição nesta década ${ }^{3}$. Seu foco de estudo baseia-se na interação genenutriente, que pode ocorrer de duas formas: nutrientes e compostos bioativos dos alimentos (CBAs) que influenciam o funcionamento do genoma e variações no genoma que influenciam a forma pela qual o indivíduo responde à dieta ${ }^{4,5}$.

Esta recente ciência tem como objetivo principal o estabelecimento de dietas personalizadas, com base no genótipo, para a promoção da saúde e a redução do risco de doenças crônicas não transmissíveis, como as cardiovasculares, o câncer, o diabetes, entre outras ${ }^{6,7}$.

Nutrientes e CBAs desencadeiam efeitos moleculares, benéficos ou não ao organismo, dependendo de quais genes apresentam sua atividade alterada ${ }^{8}$. Nesse sentido, interesse tem sido atribuído à capacidade que nutrientes e CBAs têm de alterar a expressão gênica ${ }^{4,7}$. Todo processo metabólico envolve a ação de diversas proteínas produzidas a partir de moléculas de RNA (ácido ribonucléico) mensageiro (RNAm) transcritas em uma determinada célula, em um tecido ou no organismo. Alterações nos níveis de RNAm, bem como de proteínas, incluindo transportadores, enzimas e receptores, são importantes deter- minantes do fluxo de nutrientes ou metabólitos pela via bioquímica?

Nutrientes e CBAs podem atuar em diferentes alvos moleculares ${ }^{10-13}$ e alterar todas as etapas da expressão gênica9 ${ }^{9}$. Assim, por exemplo, as vitaminas $A$ e $D$, bem como os ácidos graxos, apresentam ações diretas ao ativarem receptores nucleares e induzirem a transcrição gênica ${ }^{4}$. Compostos bioativos, como o resveratrol presente no vinho tinto e a genisteína na soja, podem também apresentar ações transcricionais, no caso indiretas, influenciando vias de sinalização molecular como a do fator nuclear kappa B (NFkB). Adicionalmente, ferro e $\beta$-caroteno ${ }^{10}$ apresentam ações pós-transcricionais, modulando a estabilidade do RNA mensageiro ou, ainda, sua tradução em proteínas nos ribossomos.

A partir da conclusão do Projeto Genoma Humano, constatou-se que os genomas dos indivíduos apresentam cerca de apenas 0,1\% de diferença em suas seqüências ${ }^{4}$. As principais variações consistem em substituições de uma única base do DNA (ácido desoxirribonucléico). Esse tipo de polimorfismo, denominado de nucleotídeo único, pode resultar na produção de proteínas com funções alteradas, com diferentes repercussões em processos como digestão, absorção e metabolismo de nutrientes e influenciar a forma pela qual se responde à alimentação ${ }^{5}$. Um exemplo interessante é o polimorfismo C677T no gene MTHFR, responsável pela conversão de homocisteína a metionina. A substituição de citosina por timina na posição 677 do gene resulta na síntese de enzima com atividade reduzida. Indivíduos com esse SNP parecem necessitar de recomendações 
aumentadas de ácido fólico. Além disso, polimorfismo no gene APOA1, principal apoproteína da HDL (lipoproteína de alta densidade), pode influenciar a forma pela qual os níveis plasmáticos dessa lipoproteína variam em função do consumo de ácidos graxos poliinsaturados ${ }^{6}$.

Do ponto de vista tecnológico, o surgimento da nutrigenômica foi favorecido pelo impressionante desenvolvimento das ferramentas ômicas ocorrido na última década, muito em parte devido ao Projeto Genoma Humano9,14. Alguns autores definem, inclusive, nutrigenômica como a aplicação de ferramentas de genômica funcional na área de nutrição ${ }^{4,6}$. Dentre essas, destacam-se as que possibilitam a análise do transcritoma (transcritômica), proteoma (proteômica) e metaboloma (metabolômica) (Figura 1). Diferentemente do genoma (conjunto do material genético), que se modifica lentamente, ao longo de gerações, o transcritoma, o proteoma e o metaboloma (conjunto em um dado momento de transcritos, proteínas e metabólitos, respectivamente) sofrem alterações constantes, em resposta a diferentes fatores ambientais, incluindo a alimentação ${ }^{9}$.

Vale ressaltar que o impacto científico das ferramentas ômicas já foi comparado, inclusive, à invenção do microscópio ${ }^{3}$. A grande vantagem dessas tecnologias é a possibilidade de analisar diferentes sistemas de forma global ${ }^{14}$. Nesse sentido, seu uso possibilita aos pesquisadores na área de nutrição elucidar questões complexas a respeito da interação gene-nutriente ${ }^{7}$. A integração das diferentes metodologias ômicas (transcritômica, proteômica e metabolômica) apresenta potencial de desenvolvimento de biomarcadores para o estado de saúde; de identificação de alterações precoces no desenvolvimento de doenças crônicas não transmissíveis; de diferenciação entre indivíduos que respondem e não respondem a intervenções dietéticas; além da descoberta de CBAs benéficos $7,9,15$.

\section{Transcritômica}

Atualmente a tecnologia de DNA microarrays (microarranjos de DNA) representa a principal ferramenta para análise transcritômica, que possibilita avaliar simultaneamente até 50 mil transcritos ${ }^{7}$. Esse alto desempenho é a grande vantagem dos microarranjos de DNA, quando comparados a metodologias tradicionais como RT-PCR (reverse transcriptase - polymerase chain reaction; transcrição reversa - reação em cadeia da polimerase), real time PCR; PCR em tempo real; northern blots e differential displays ${ }^{16}$ que permitem, geralmente, a análise de um transcrito por vez, por meio de amplificação por PCR ou

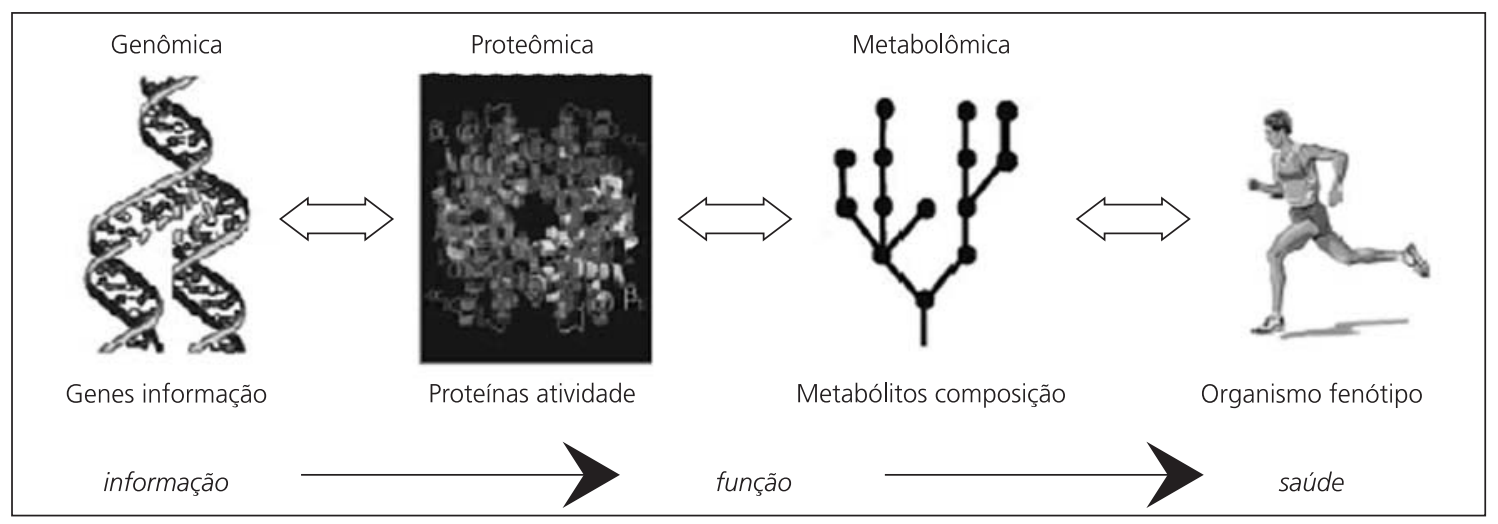

Figura 1. Ferramentas ômicas na nutrição e saúde. Genômica, proteômica e metabolômica integradas na Ciência da Nutrição e na promoção de saúde.

Nota: Nutrição no pós genoma: fundamentos e aplicações de ferramentas ômicas. Adaptado de Kussman et al. ${ }^{5}$. 
hibridização, ou, ainda, por meio de seqüenciamentos de DNA complementar (cDNA).

O conhecimento da seqüência do genoma humano foi fundamental para que se pudesse estudar o componente transcritômico completo. Contudo, por não terem sido completamente caracterizados o proteoma e o metaboloma humanos, a maioria dos estudos na área de nutrigenômica tem tido como foco a análise do RNAm . Desse modo, a análise transcritômica permite avaliação inicial global a respeito da atividade dos genes ${ }^{7}$ e serve para situar a análise proteômica e metabolômica em uma perspectiva biológica mais ampla ${ }^{5}$.

Como vantagens adicionais dos microarranjos de DNA ressalta-se a possibilidade de elucidar, de forma holística, as vias moleculares afetadas por nutrientes e compostos bioativos dos alimentos e, além disso, o estabelecimento de novas hipóteses de estudo, mais direcionadas e que, muitas vezes, não seriam consideradas a princípio ${ }^{5,17}$.

A tecnologia de microarranjos de DNA baseia-se na capacidade de moléculas de DNA em fita simples de se hibridizarem a seqüências complementares de DNA. Os arranjos consistem em milhares de seqüências de DNA, cada uma representando um gene, organizadas de forma ordenada em uma matriz de vidro, semelhante a uma lâmina de microscópio. O conhecimento das seqüências de DNA (probes - sondas) permite a quantificação da abundância de transcritos específicos em uma amostra biológica ${ }^{16}$.

Cada experimento de microarranjo de DNA consiste em 5 etapas: (1) produção do microarranjo; (2) extração de RNA da amostra biológica; (3) hibridização dos ácidos nucléicos marcados com o microarranjo; (4) detecção do sinal e visualização dos dados; (5) processamento e análise dos dados ${ }^{18}$.

Os microarranjos podem conter como sondas, moléculas de cDNA ou oligonucleotídeos. No primeiro caso, o cDNA é imobilizado em matriz de vidro por meio de robôs. Já no segundo caso, os oligonucleotídeos (20 a 25 bases) podem ser imobilizados mecanicamente ou, mais comumente, sintetizados in loco na própria matriz de vidro, por meio de processo denominado fotolitografia. Microarranjos com cDNA são produzidos principalmente em ambientes acadêmicos, enquanto aqueles com oligonucleotídeos são comercializados por empresas ${ }^{16,18}$.

Freqüentemente, o RNA (alvo) a ser hibridizado com as sondas no arranjo é extraído de amostras biológicas representadas por tecidos. São necessários de 10 a 40 $\mu \mathrm{g}$ de RNA de alta qualidade. Após sua purificação, o RNA é reversamente transcrito em CDNA, sendo marcado com fluoróforos. O uso de 2 fluoróforos (normalmente verde e vermelho) permite que duas amostras (tumor $x$ tecido normal; célula não tratada $x$ a tratada, por exemplo) sejam analisadas simultaneamente em uma mesma hibridização, utilizando-se um único arranjo. Após cerca de 16 a 24 horas de hibridização, os arranjos são lavados e escaneados ${ }^{16,18}$.

Os scanners utilizados na tecnologia de microarranjos de DNA contêm filtros de emissão e excitação que permitem detectar os dois fluoróforos utilizados. Assim, a intensidade de fluorescência medida será reflexo do número de moléculas de cDNA contendo cada fluoróforo (verde ou vermelho) hibridizado ao array ${ }^{18}$. A partir dessa etapa, geram-se os dados brutos. A quantidade imensa de informações produzidas por essa ferramenta de biologia molecular de alto desempenho representa grande desafio para sua análise, sendo fundamental o papel da bioinformática nesse sentido. A partir de algoritmos complexos e utilizando softwares específicos, estatísticos e matemáticos buscam agrupar os resultados de forma biologicamente significativa. Uma vez que genes diferencialmente expressos são identificados, análises mais detalhadas e confirmatórias são, então, conduzidas com técnicas como northern blots e RT-PCR ${ }^{16,18}$.

Exemplos da aplicação de microarranjos de DNA na pesquisa em nutrição são estudos em que se avaliaram, em culturas de células, animais de experimentação e seres humanos, alvos mole- 
culares de nutrientes e $\mathrm{CBAs}^{7}$. O tratamento de células de carcinoma de cólon com sulforafano, composto bioativo de brócolis, resultou na indução e na inibição da expressão de 106 e 63 genes, respectivamente ${ }^{19}$. De acordo com a análise da expressão gênica diferencial, as ações anticarcinogênicas desse CBAs envolveriam modulação do metabolismo de ácidos graxos, indução da diferenciação celular e inibição de hipermetilação do DNA $^{19}$.

Hoekstra et al. ${ }^{20}$ aplicaram a técnica de microarray para analisar as vias e os genes envolvidos na resposta de células parenquimatosas hepáticas a concentrações crescentes de lipídeos, sob condições aterogênicas. O tratamento de camundongos deficientes no receptor de LDL (lipoproteína de baixa densidade) com dieta ocidentalizada (15,00\% de manteiga de cacau e $0,25 \%$ de colesterol) resultou em aumento rápido e substancial (16 a 22 vezes) na expressão do gene FABP5 (proteína ligadora de ácido graxo 5) e de mais 4 novos genes com função semelhante. De acordo com os autores, esses genes apresentariam papel importante na proteção das células hepáticas contra a toxicidade induzida por colesterol, ácidos graxos livres e lipídeos oxidados.

Indivíduos com síndrome metabólica que consumiram durante 12 semanas dietas com carboidratos provenientes, principalmente, de centeio e macarrão (resposta reduzida de insulina) ou de trigo, aveia e batata (resposta elevada de insulina) apresentaram diferentes alterações na expressão gênica no tecido adiposo subcutâneo ${ }^{21}$. Enquanto a $1^{\text {a }}$ dieta reduziu a expressão de 71 genes relacionados à sinalização de insulina e apoptose, a $2^{\mathrm{a}}$ induziu a expressão de 62 genes, associados ao estresse metabólico. Esses resultados destacam que a composição da dieta pode ter importantes repercussões na regulação gênica ${ }^{21}$.

Apesar das vantagens da técnica de microarranjos de DNA, existem, ainda, importantes limitações para aplicação dessa ferramenta na área de nutrição, principalmente em estudos envolvendo seres humanos. Uma delas se refere à necessidade de quantidades significativas de tecidos para o isolamento do RNAm. Apesar de o uso de células sanguíneas representar alternativa, tem-se verificado, nesse caso, amplas variações interindividuais no perfil de expressão gênica, o que limita a análise do efeito de intervenções nutricionais ${ }^{7}$. A necessidade de repetições para obter resultados significantes e o alto custo da técnica resultam também em limitação econômica. Tratamentos com nutrientes e CBAs promovem, geralmente, pequenas alterações na expressão gênica, o que dificulta a análise dos resultados e exige o desenvolvimento de complexos algoritmos. Também a pequena reprodutibilidade dos resultados utilizando-se plataformas de diferentes fabricantes ${ }^{15}$ tem estimulado iniciativas para padronizar, por meio de boas práticas analíticas, os experimentos de microarranjos de DNA na área de nutrição ${ }^{22}$.

Estima-se que, apesar de apresentar cerca de 30 mil genes, o genoma humano é capaz de expressar mais de 100 mil proteínas ${ }^{15}$. Assim, ressalta-se que a análise do transcritoma deve ser complementada pela do proteoma e do metaboloma.

Embora a principal aplicação dos microarranjos de DNA seja a análise da expressão gênica global, essa técnica tem sido utilizada também para outras finalidades que incluem a análise de $\mathrm{SNPS}^{23}$. Considerando-se a estimativa de 10 milhões desses polimorfismos no genoma humano, essa plataforma representa alternativa promissora para genotipagem em larga escala ${ }^{24}$. $\mathrm{Na}$ área de Nutrição, acredita-se que os microarranjos de DNA venham a auxiliar na predição das necessidades nutricionais individuais, resposta a dietas e risco para doenças crônicas não transmissíveis ${ }^{23}$.

\section{Proteômica}

Em virtude de as proteínas serem moléculas centrais em diferentes funções biológicas e candidatas a alvos terapêuticos, as ferramentas de proteômica têm apresentado avanço progressivo. No início da década de 1990, proteoma 
equivalia ao conceito de genoma. Atualmente, proteômica é o gap entre a seqüência do genoma e o comportamento celular, o que permite afirmar ser uma importante ferramenta biológica para a determinação da função gênica. Em função do número de genes humanos conhecidos, uma célula pode expressar cerca de 20 mil diferentes proteínas. Considerando uma massa molecular média de 50kDa, e conteúdo médio de lisina e arginina, então cada proteína gerará aproximadamente 30 peptídeos trípticos. Sendo assim, proteínas de uma célula podem gerar 6 milhões de peptídeos trípticos ${ }^{1,2}$.

Inicialmente, a proteômica foi utilizada para descrever o estudo de proteínas expressas de um genoma ao utilizar eletroforese em gel 2D ou bidimensional e espectrometria de massa para separar e identificar proteínas, acrescido de ferramentas sofisticadas de bioinformática para descodificar e interpretar os dados (Figura 2) 1,25. $^{2}$. Proteômica inclui não somente a identificação e quantificação de proteínas, mas também determina sua localização, modificações, interações, atividades e funções ${ }^{26}$. Assim, pode-se considerar que o estudo com proteínas torna-se mais complexo do que com ácidos nucléicos, uma vez que estas podem ser modificadas pós traducionalmente por meio de fosforilação, glicosilação, ubiquitinização, sulfatação ou acetilação. Adicionalmente, proteínas respondem diferentemente dependendo da localização celular, sofrem proteólise, se desestruturam e rearranjam de acordo com o que ligam, como ácidos nucléicos, outras proteínas, lipídeos, moléculas de baixo peso molecular e outros ligantes, e os níveis de proteínas não refletem necessariamente os níveis de $\mathrm{RNAm}^{27}$. Finalmente, uma única proteína pode estar envolvida em mais de um processo e, inversamente, funções similares podem ser executadas por diferentes proteínas ${ }^{26}$. Todas essas possibilidades resultam que o proteoma apresenta uma maior complexidade comparada ao genoma e, de maneira geral, pode-se afirmar que um genoma pode apresentar muitos proteomas.

As seguintes tecnologias são cruciais em proteômica para elucidar a função de um determinado gene: preparo da amostra, separação e identificação de proteínas, determinação da seqüência parcial de aminoácidos e bioinformática (ciência na qual informações obtidas das proteínas são cruzadas com o banco de dados genômicos) $)^{28}$.

O modelo experimental e o cuidado no preparo da amostra são vitais para a obtenção de resultados reprodutíveis, principalmente na proteômica comparativa. Podem ser utilizados tecidos de animais, cultura de células, fluidos biológicos, plantas, bactérias e vírus. Normalmente as amos-

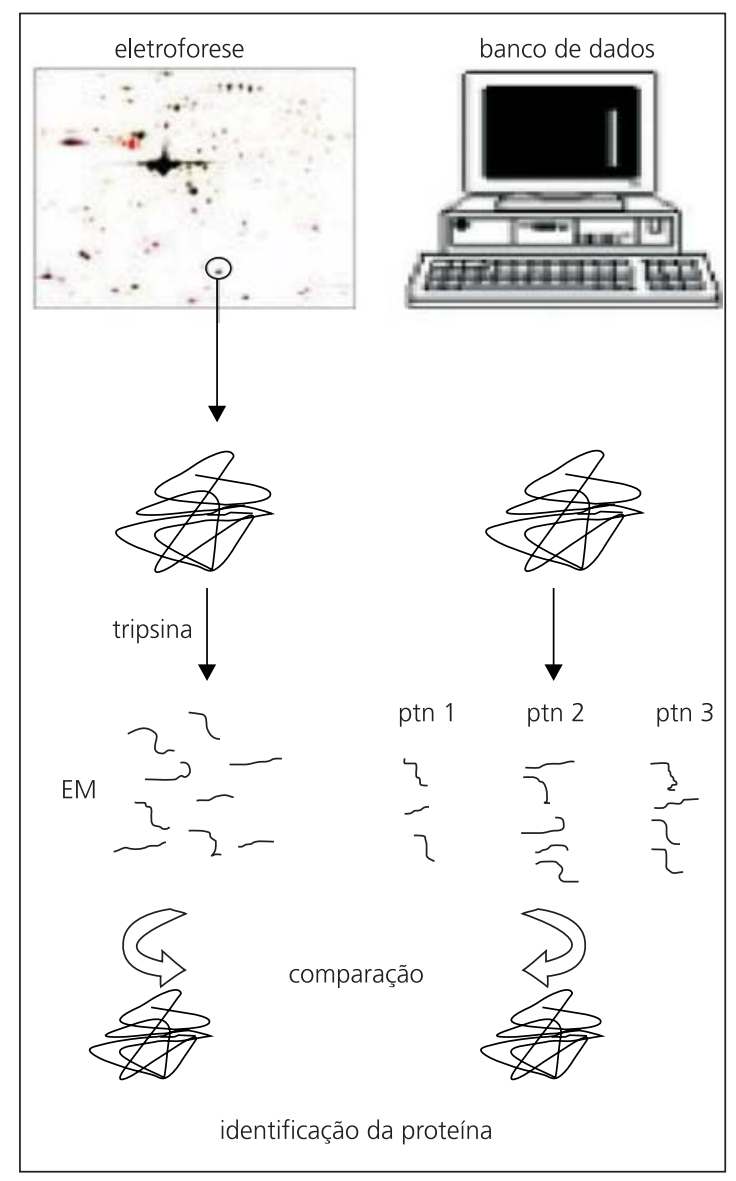

Figura 2. Análise de proteínas por espectrometria de massa (EM). Em um gel bidimensional diversos spots são corados. Tais spots são extraídos, as proteínas são tripsinizadas e seus fragmentos são analisados por EM. Por meio da bioinformática as seqüências obtidas são comparadas às armazenadas no banco de dados.

Nota: Adaptado de Carbonaro 33 . 
tras biológicas utilizadas são muito complexas e torna-se necessário realizar um pré-fracionamento ou enriquecimento das proteínas de interesse. As amostras podem ser enriquecidas por precipitação, centrifugação, cromatografias, eletroforese, dentre outros métodos bioquímicos o que proporciona a obtenção da proteína mais concentrada. Tais procedimentos tornam-se cruciais, pois normalmente as proteínas se encontram em concentrações reduzidas e são as moléculas que carregam informações diagnósticas importantes envolvidas em diversos processos celulares ${ }^{29}$.

A análise por espectrometria de massa (EM) requer inicialmente que a mistura de proteínas seja fracionada e, de preferência, que as proteínas de interesse sejam digeridas em peptídeos por proteases, normalmente a tripsina. Para obtenção da proteína, três principais métodos de separação podem ser utilizados, ou seja: eletroforese uni ou bidimensional na presença de dodecil sulfato de sódio (1D ou 2D-SDS-PAGE) e isoeletrofocalização (IEF). Além desses métodos, outras alternativas existem, particularmente a cromatografia líquida de alta eficiência (CLAE), por meio da utilização de colunas de fase reversa, afinidade, filtração em gel, troca iônica, dentre outras $^{1,5}$. A EM é uma técnica sensível e seletiva, capaz de produzir e separar íons de acordo com a razão massa-carga, o que permite gerar em pouco tempo informações acerca do peso molecular e da estrutura do composto.

A metodologia baseada na degradação de Edman foi muito utilizada para a identificação e o sequenciamento de proteínas ${ }^{30,31}$ porém, John B. Fenn e Koichi Tanaka, ganhadores do prêmio Nobel de Química em 2002, inovaram em dois instrumentos de EM denominados MALDI-TOF (Matrix-assisted laser desorption/ionization ou ionização por desorção a laser assistida por matriz) e ESI (electrospray ionization ou ionização eletrospray) tandem. O termo tandem significa a utilização seqüencial de dois espectrômetros de massa, o que torna excelente para a identificação de proteínas quando não se tem o genoma descrito. Sabe-se que existem três tipos de analisadores comumente utilizados com fonte ESI: triple quadrupole ou triplo quadrupólo ou triple quad, ion trap e quadrupole time of flight ou tempo de vôo quadrupólo (Q-TOF). Os quadrupólos são considerados filtros que permitem a entrada no sistema de análise do espectrômetro de massa. O FT-ICR (Fourier transform ion cyclotron resonance ou ressonância de íon ciclotron de transformada ou transformação de Fourier), conhecido também como FT-MS é análogo ao ion trap; contudo, o analisador da massa emprega um campo magnético em uma amostra protéica que não sofreu ação de proteases ou outros procedimentos químicos, e o algoritmo de transformação de Fourier detecta todos os íons no trap simultaneamente ${ }^{1,32-36}$.

Modificações pós traducionais de proteínas representam os principais determinantes da complexidade de organismos superiores. São conhecidos mais de 200 diferentes tipos, sendo a maioria irreversível e importante na regulação de processos biológicos. A importância e o papel da fosforilação/ desfosforilação de proteínas se dá pelo elevado número de proteínas quinases e fosfatases presentes no genoma humano, que constitui cerca de $2 \%$ de todos os genes ${ }^{37,38}$. Existe uma ramificação do proteoma denominada fosfoproteoma e diferentes estratégias de detecção dos níveis de fosforilação de proteínas podem ser realizadas, tais como: purificação de fosfoproteínas por cromatografias de afinidade como IMAC (Immobilized Metal Ion Affinity Chromatography ou Cromatografia de Afinidade por ĺon Metal Imobilizado), marcação com radioisótopos, imunoprecipitação e western blotting utilizando anticorpos específicos, corantes específicos para fosfoproteínas como o Pro-Q diamond dye e detecção de fosfoproteínas utilizando fosfatases recombinantes ou não 2,39.

Um número crescente de estudos com proteoma objetiva identificar respostas celulares a constituintes dietéticos, bem como seus alvos moleculares. Por exemplo, estudos com flavonóides, como as catequinas presentes no chá verde ${ }^{40}$, proantocianidinas presentes no extrato de semente de $\mathrm{uva}^{41}$ ou isoflavonas e flavonas de soja ${ }^{42,43}$ associam a bioatividade aos achados epidemiológicos, e sugerem que metabólitos secundários de plantas apresentam relevância na promoção da saúde. Além disso, alguns nutrientes, 
como zinco e ácidos graxos poliinsaturados, estão sendo estudados em sistemas de cultura de células e em cobaias por meio de transcritômica, proteômica e metabolômica para definir mecanismos moleculares associados ao metabolismo ${ }^{9,44}$.

A proteômica se aplica também na análise qualitativa de alimentos via matriz alimentar e no estudo da interação proteína-proteína em alimentos crús e/ou processados, bem como nas interações entre proteínas e outros componentes alimen$\operatorname{tares}^{28,33}$. Como exemplos podemos citar mudanças na qualidade das carnes post mortem e interações de proteínas musculares com lipídeos, carboidratos e outros constituintes alimentares ${ }^{45,46}$, em cereais por meio da avaliação da qualidade de gliadina na produção de pães ${ }^{47}$, ocorrência de microrganismos e alérgenos em alimentos, análises de peptídeos bioativos presentes em leite humano e provável utilização em fórmulas lácteas ${ }^{33}$, dentre outras aplicabilidades.

\section{Metabolômica}

Alterações na expressão gênica apresentam a limitação de apenas indicar o potencial de ocorrência de alterações fisiológicas ${ }^{7}$. Nesse sentido, é fundamental entender as conseqüências metabólicas de alterações na síntese de RNAm e proteínas $^{48}$. Metabolômica representa a análise quali e quantitativa do conjunto total de metabólitos de baixo peso molecular (<1500Da) em um dado sistema biológico e determinado momento ${ }^{48,49}$. As moléculas incluem peptídeos, aminoácidos, ácidos nucléicos, carboidratos, ácidos orgânicos, vitaminas, polifenóis, alcalóides, minerais, bem como qualquer outra substância química ingerida ou sintetizada por uma célula ou organismo ${ }^{50}$.

A análise metabolômica é bastante complexa visto que o metaboloma varia de acordo com o tempo e localização biológica. Nesse sentido, órgãos, células em um órgão e compartimentos intracelulares apresentam metabolomas distintos, que podem ser influenciados por fatores como sexo, genótipo, estado hormonal, exercício físico, estresse e alimentação9.

As principais técnicas para análise metabolômica em fluidos humanos são a cromatografia gasosa (GC) ou líquida (LC), acopladas a EM ou espectroscopia de ressonância nuclear magnética $(\mathrm{NMR})^{9}$. Essas duas últimas técnicas são complementares e utilizadas em paralelo em estudos metabolômicos ${ }^{5}$. Permitem, atualmente, a identificação de apenas frações do metaboloma humano ${ }^{48}$, estimado em cerca de 10 mil metabólitos ${ }^{5}$.

A metabolômica se aplica, essencialmente, à nutrição molecular e inclui análises de componentes alimentares, qualidade alimentar, monitoramento do consumo alimentar e fisiológico por meio de intervenção alimentar e/ou de estudos com modificações dietéticas ${ }^{50}$.

As concentrações de alguns metabólitos, como colesterol e glicose, em amostras de sangue ou urina têm sido utilizadas rotineiramente como indicadores do estado de saúde. A metabolômica tem sido empregada em estudos pré-clínicos e clínicos e nesse contexto, o aspecto inovador desta ciência relaciona-se à possibilidade de estabelecer novos biomarcadores de doenças ou padrões metabólicos associados ao estado nutricional, por meio da caracterização total de pequenas moléculas em amostras biológicas, especialmente influenciadas por variações nutricionais ${ }^{49-51}$.

\section{O N CLUSÃ O}

$\mathrm{Na}$ atual era do pós-genoma, diferentes oportunidades e desafios surgem no contexto da pesquisa em Nutrição. Ferramentas ômicas representam enorme potencial para elucidar a complexa relação entre nutrição e saúde e estabelecer as melhores recomendações dietéticas individuais para a redução do risco das doenças crônicas não transmissíveis e a promoção da saúde ${ }^{7}$. Em um futuro próximo, serão acumulados dados suficientes e novas ferramentas serão necessárias para facilitar as análises das disciplinas ômicas e interpretar os resultados por meio da bioinformática. Tais avanços fornecerão novas descobertas e aplicabilidades na Ciência da Nutrição. 


\section{COLABORADORES}

E. FIALHO elaborou os itens introdução, proteômica e conclusões. F.S. MORENO elaborou os itens transcritômica, metabolômica e conclusões. T.P. ONG elaborou os itens introdução, transcritômica e conclusões.

\section{REFERÊ NCIAS}

1. Lieble DC. Introduction to proteomics. Tools for the new biology. Totowa: Humana Press; 2002.

2. Simpson RJ. Proteins and proteomics. A laboratory manual. New York: Cold Spring Harbor Laboratories Press; 2003.

3. Fairweather-Tait SJ. Human nutrition and food research: opportunities and challenges in the post-genomic era. Phil Trans S Royal Lond B. 2003; 358(1438):1709-27.

4. Kaput J, Rodriguez RL. Nutritional genomics: the next frontier in the postgenomic era. Physiol Genomics. 2004;16(2):166-77.

5. Kussmann M, Raymond F, Affolter M. OMICSdriven biomarker discovery in nutrition and health. J Biotechnol. 2006; 124(4):758-87.

6. DeBusk RM, Fogarty CP, Ordovas JM, Kornman KS. Nutritional genomics in practice: where do we begin? JADA. 2005;105(4):589-98.

7. Zhang X, Yap Y, Wei D, Chen G, Chen F. Novel omics technologies in nutrition research. Biotechnol Adv. 2008; 26(2):169-76.

8. Hirsch JB, Evans D. Beyond the impact of food on genes. Food Technol. 2005; 59(7):24-33.

9. Rist MJ, Wenzel U, Daniel H. Nutrition and food science go genomic.Trends Biotechnol. 2006; 24(4):172-8.

10. Moreno FS, Rossiello MR, Manjeshwar S, Nath R, Rao PM, Rajalakshmi S, et al. Effect of betacarotene on the expression of 3-hydroxymethylglutaryl coenzyme $A$ reductase in rat liver. Cancer Lett. 1995; 96(2):201-8.

11. Naves MM, Silveira ER, Dagli ML, Moreno FS. Effects of beta-carotene and vitamin A on oval cell proliferation and connexin 43 expression during hepatic differentiation in the rat. Nutr Biochem. 2001;12(12):685-92.

12. Espíndola RM, Mazzantini RP, Ong TP, Conti A, Heidor R, Moreno FS. Geranylgeraniol and betaionone inhibit hepatic preneoplastic lesions, cell proliferation, total plasma cholesterol and DNA damage during the initial phases of hepatocarcinogenesis, but only the former inhibits NF-kappaB activation. Carcinogenesis. 2005; 26(6):1091-9.

13. Ong TP, Heidor R, Conti A, Dagli ML, Moreno FS. Farnesol and geraniol chemopreventive activities during the initial phases of hepatocarcinogenesis involve similar actions on cell proliferation and DNA damage, but distinct actions on apoptosis, plasma cholesterol and HMGCoA reductase. Carcinogenesis. 2006; 27(6):1194-203.

14. Ghosh D, Skinner MA, Laing WA. Pharmacogenomics and nutrigenomics: synergies and differences. Eur J Clin Nutr. 2007; 61(5):567-74.

15. Kussmann M, Affolter M. Proteomic methods in nutrition. Curr Opin Clin Nutr Metab Care. 2006; 9(5):575-83.

16. Spielbauer B, Stahl F. Impact of microarray technology in nutrition and food research. Mol Nutr Food Res. 2005; 49(10):908-17.

17. Mutch DM, Wahli W, Williamson G. Nutrigenomics and nutrigenetics: the emerging faces of nutrition. FASEB J. 2005; 19(12):1602-16.

18. Pozhitkov AE, Tautz D, Noble PA. Oligonucleotide microarrays: widely applied-poorly understood. Brief Funct Genomic Proteomic. 2007; 6(2):141-8.

19. Traka M, Gasper AV, Smith JA, Hawkey CJ, Bao Y, Mithen RF. Transcriptome analysis of human colon Caco-2 cells exposed to sulforaphane. J Nutr. 2005; 135(8):1865-72.

20. Hoekstra M, Stitzinger M, van Wanrooij EJ, Michon IN, Kruijt JK, Kamphorst J, et al. Microarray analysis indicates an important role for FABP5 and putative novel FABPs on a Western-type diet. Lipid Res. 2006; 47(10):2198-207.

21. Kallio $P$, Kolehmainen $M$, Laaksonen DE, Kekäläinen J, Salopuro T, Sivenius K, et al. Dietary carbohydrate modification induces alterations in gene expression in abdominal subcutaneous adipose tissue in persons with the metabolic syndrome: the FUNGENUT Study. Am J Clin Nutr. 2007; 85(5): 1417-27.

22. Garosi P, De Filippo C, van Erk M, Rocca-Serra P, Sansone SA, Elliott R. Defining best practice for microarray analyses in nutrigenomic studies. $\mathrm{Br} \mathrm{J}$ Nutr. 2005; 93(4):425-32.

23. Liu-Stratton $Y$, Roy S, Sen CK. DNA microarray technology in nutraceutical and food safety. Toxicol Lett. 2004;150(1):29-42.

24. Lovmar L, Syvänen AC. Genotyping singlenucleotide polymorphisms by minisequencing using tag arrays. Methods Mol Med. 2005;114: 79-92. 
25. Pandey A, Mann M. Proteomics to study genes and genome. Nature. 2000; 405(6788), 837-46.

26. Fields, S. Proteomics: proteomics in genomeland. Science. 2001; 291(5507):1221-4.

27. Gygi SP, Rochon Y, Franza BR, Aebersold R. Correlation between protein and mRNA abundance in yeast. Mol Cell Biol. 1999; 19(3): 1720-30.

28. Kvasnicka V. Proteomics: general strategies and application to nutritionally relevant proteins. J Chromatogr B Analyt Technol Biomed Life Sci. 2003; 787(1):77-89.

29. Bodzon-Kulakowska A, Bierczynska-Krzysik A, Dylag T, Drabik A, Suder P, Noga M, et al. Methods for samples preparation in proteomic research. J Chromatogr B Analyt Technol Biomed Life Sci. 2007; 849(1):1-31.

30. Matsudaira PT. Sequence from picomole quantities of proteins electroblotted onto polyvinylidene difluoride membranes. J Biol Chem. 1987; 262(21): 10035-8.

31. Cañas B, Lopez-Ferrer D, Ramos-Fernandez A, Camafeita E, Calvo E. Mass spectrometry technologies for proteomics. Brief Funct Genomic Proteomic. 2006; 4(4):295-320.

32. Buchanan MV, Hettich RL. Fourier transform mass spectrometry of high-mass biomolecules. Anal Chem. 1993; 65(3):245A-59A.

33. Carbonaro, M. Proteomics: present and future in food quality evaluation. Trends in Food Sci \& Technol. 2004; 15(3-4):209-16.

34. Ge Y, Lawhorn BG, ElNaggar M, Strauss E, Park JH, Begley TP, et al. Top down characterization of larger proteins (45 kDa) by electron capture dissociation mass spectrometry. J Am Chem Soc. 2002; 124(4): 672-8.

35. Jonscher KR, Yates JR. The quadrupole ion trap mass spectrometer: a small solution to a big challenge. Anal Biochem. 1997; 244(1):1-15.

36. Yates JR. Mass spectrometry and the age of the proteome. J Mass Spectrom. 1998; 33(1): 1-19.

37. Venter JC, Adams MD, Myers EW, Li PW, Mural RJ, Sutton $G G$, et al. The sequence of the human genome. Science. 2001; 291(5507):1304-51.

38. Manning G, Whyte DB, Martinez R, Hunter T, Sudarsanam $\mathrm{S}$. The protein kinase complement of the human genome. Science. 2002; 298(5600): 1912-34.

39. Raggiaschi R, Gotta S, Terstappen GC. Phosphoproteome analysis. Biosci Rep. 2005; 25(1/2):33-34.
40. McLoughlin P, Roengvoraphoj M, Gissel C, Hescheler J, Certa U, Sachinidis A. Transcriptional responses to epigallocatechin-3 gallate in HT 29 colon carcinoma spheroids. Genes Cells. 2004; 9(7):661-9.

41. Deshane, J, Chaves L, Sarikonda KV, Isbell S, Wilson $\mathrm{L}$, Kirk $\mathrm{M}$, et al. Proteomics analysis of rat brain protein modulations by grape seed extract. J Agric Food Chem. 2004; 52(26):7872-83.

42. Fuchs D, Erhard P, Rimbach G, Daniel H, Wenzel U. Genistein blocks homocysteine-induced alterations in the proteome of human endothelial cells. Proteomics. 2005; 5(11):2808-18.

43. Solanky KS, Bailey N-J; Beckwith-Hall BM, Bingham S, Davis A, Holmes E, et al. Biofluid 1H NMR-based metabonomic techniques in nutrition research metabolic effects of dietary isoflavones in humans. J Nutr Biochem. 2005; 16(4):236-44.

44. Dieck H, Döring F, Fuchs D, Roth H-P, Daniel $H$. Transcriptome and proteome analysis identifies the pathways that increase hepatic lipid accumulation in zinc-deficient rats. J. Nutr. 2005; 135(2): 199-205.

45. Roncada P, Gaviraghi A, Greppi GF, Gigli S. A proteomic approach to compare meat from different species. Proceedings of the 48th International Congress of Meat Science Anal Tecnology; 2002 Ago 25-30; Roma; 2002. v.2, p. 640-41.

46. Lametsch R, Bendixen E. Proteome analysis applied to meat science: characterizing post mortem changes in porcine muscle. J Agric Food Chem. 2001; 49(10):4531-7.

47. Gottlieb D M, Schultz J, Petersen M, Nesic L, Jacobsen S, Sondergaard I. Determination of wheat quality by mass spectrometry and multivariate data analysis. Rapid Commun Mass Spectrom. 2002;16(21):2034-9.

48. Astle J, Ferguson JT, German JB, Harrigan GG, Kelleher NL, Kodadek T, et al. Characterization of proteomic and metabolomic responses to dietary factors and supplements. J Nutr. 2007; 137(12): 2787-93.

49. Trujillo E, Davis C, Milner J. Nutrigenomics, proteomics, metabolomics, and the practice of dietetics. JADA. 2006; 106(3):403-13.

50. Wishart DS. Metabolomics: applications to food science and nutrition research. Trends in Food Sci Technol. 2008. Article in press.

51. Whitfield PD, German AJ, Noble PJ. Metabolomics: an emerging post-genomic tool for nutrition. $\mathrm{Br} J$ Nutr. 2004; 92(4):549-55.

Recebido em: 2/6/2008 Aprovado em: 29/9/2008 